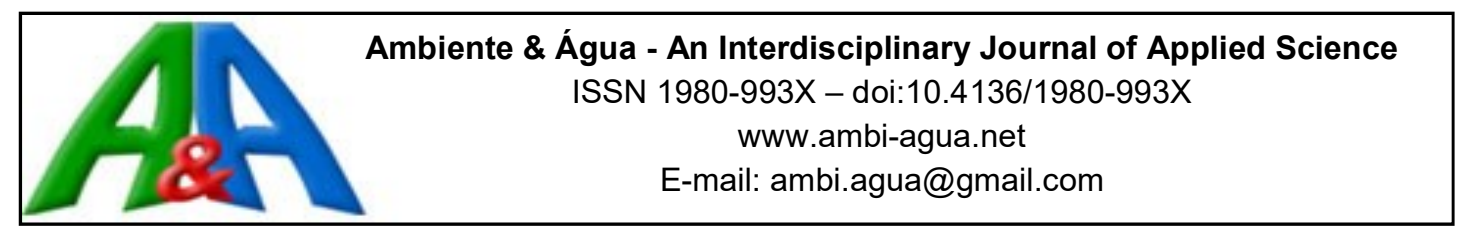

\title{
Metais potencialmente tóxicos em rios a montante do Pantanal Norte
}

doi:10.4136/ambi-agua.1827

Received: 04 Feb. 2016; Accepted: 12 Sep. 2016

\author{
Geizibel Campos de Magalhães ${ }^{1}$; Ibraim Fantin-Cruz ${ }^{2}$; \\ Peter Zeilhofer ${ }^{3}$; Eliana Freire Gaspar de Carvalho Dores ${ }^{4^{*}}$ \\ Universidade Federal de Mato Grosso (UFMT), Cuiabá, MT, Brasil \\ ${ }^{1}$ Departamento de Programa de Pós-Graduação em Recursos Hídricos \\ ${ }^{2}$ Departamento de Engenharia Sanitária e Ambiental \\ ${ }^{3}$ Departamento de Geografia \\ ${ }^{4}$ Departamento de Química \\ *Autor correspondente: e-mail: eliana@ufmt.br, \\ geizim05@hotmail.com, ibraimfantin@gmail.com, \\ zeilhoferpeter@gmail.com
}

\section{RESUMO}

Os rios Cuiabá (CBA) e São Lourenço (SL) são considerados estratégicos por integrar regiões de grande relevância econômica, social e ambiental para o Brasil e o mundo. Porém, diversas atividades nas bacias destes rios podem representar fontes de metais potencialmente tóxicos e comprometer a sua qualidade ambiental. Neste trabalho foi avaliada a variabilidade espacial e temporal da concentração de metais nestas bacias e a sua relação com parâmetros de qualidade da água. Foram coletadas mensalmente, de agosto/2012 a julho/2013, 15 amostras de água superficial e 9 amostras de sedimento de fundo, nos rios CBA e SL. As concentrações de $\mathrm{Cr}, \mathrm{Cu}, \mathrm{Fe}, \mathrm{Mn}, \mathrm{Pb}$ e $\mathrm{Zn}$ nas amostras de água foram determinadas por espectrometria de emissão óptica com plasma acoplado indutivamente, e nas amostras de sedimento de leito, por espectrometria de absorção atômica com atomização em chama. Os elementos $\mathrm{Fe}, \mathrm{Mn}, \mathrm{Pb}$ e $\mathrm{Cr}$ apresentaram elevadas concentrações nas amostras de água e sedimento, porém apenas $\mathrm{Pb}$ e $\mathrm{Cr}$ representam potencial risco ambiental. As concentrações de Fe e $\mathrm{Mn}$ foram mais elevadas na parte alta do rio SL enquanto as concentrações de $\mathrm{Cu}$ e $\mathrm{Pb}$ ocorreram na área dos centros urbanos. Temporalmente, os metais estiveram associados ao regime pluviométrico. A correlação observada entre metais indica uma fonte comum. Desta maneira, a ocorrência e concentração de metais nos rios CBA e SL mostram contribuição de origem natural, reflexo do tipo de solo associado ao regime pluviométrico da região, bem como contribuição antrópica devido às atividades agropecuárias e ao lançamento de efluentes urbanos não tratados.

Palavras-chave: água, poluição, sedimento de leito.

\section{Potentially toxic metals in rivers upstream of Pantanal Norte}

\begin{abstract}
Cuiabá (CBA) and São Lourenço (SL) rivers are considered strategic once they integrate regions, which are economically, socially and environmentally relevant for Brazil and the world. However, several activities developed in their watersheds may represent sources of
\end{abstract}


metals and be a threat to the environmental quality. Thus, in this study we evaluated the spatial and temporal variability of potentially toxic metals in water and sediment and the relationship of their concentration with water quality parameters. Surface water samples were collected monthly in 15 points and bottom sediment in nine points distributed throughout both rivers from August 2012 to July 2013. Cr, Cu, Fe, Mn, Pb and $\mathrm{Zn}$ were determined in water by inducted coupled plasma optical emission spectrometry and in sediment by flame atomic absorption spectrometry. $\mathrm{Fe}, \mathrm{Mn}, \mathrm{Pb}$ and $\mathrm{Cr}$ had high concentrations in water and sediment but only $\mathrm{Pb}$ and $\mathrm{Cr}$ represent environmental risk. Fe and $\mathrm{Mn}$ were in higher concentrations in at the upper points of SL River and $\mathrm{Cu}$ and $\mathrm{Pb}$ in the urban area of both rivers. Temporally, the metal concentrations were associated with precipitation variation. The observed correlations amongst metal concentrations indicate common sources. Thus, the metals occurrence and concentrations in water and sediment of both rivers showed a natural contribution, as a reflex of soil type associated to the region's precipitation regimen as well as the anthropic contribution due to agricultural and cattle breeding activities, and disposal of untreated urban effluents.

Keywords: bed sediment, contamination, water.

\section{INTRODUÇÃO}

Dentre os aspectos de qualidade de água que trazem preocupação, a possível poluição por metais potencialmente tóxicos é especialmente importante dada a sua elevada resistência à degradação e ao potencial de bioacumulação no sistema aquático (Ikem et al., 2003; Moraes e Jordão, 2002; Ahmad et al., 2014). Ao persistir no sistema aquático, a concentração do metal é gradualmente aumentada e consequentemente absorvida pelos organismos e/ou no sedimento (Rodrigues e Formoso, 2006; Arai et al., 2007).

Inúmeras atividades podem representar fontes de metais potencialmente tóxicos para o ambiente aquático. A agricultura, por exemplo, constitui uma das mais importantes fontes difusas de poluição por metais em corpos d'água. O escoamento superficial das águas de chuva é o principal meio de transporte dos metais presentes no solo para os rios (Queiroz, 2006; Vinodhini e Narayanan, 2008). Produtos utilizados na atividade agropecuária, tais como os fertilizantes $(\mathrm{Cd}, \mathrm{Cr}, \mathrm{Pb}, \mathrm{Zn})$, os pesticidas $(\mathrm{Cu}, \mathrm{Pb}, \mathrm{Mn}, \mathrm{Zn})$, os preservativos de madeira $(\mathrm{Cu}, \mathrm{Cr})$ e dejetos de produção intensiva de bovinos, suínos e aves $(\mathrm{Cu}, \mathrm{Mn}$ e $\mathrm{Zn})$ são as principais fontes de metais potencialmente tóxicos (Núnez et al., 1999; Ramalho et al., 2000; Santos et al., 2002; Kunz et al., 2005; Costa, 2007; Bizarro et al., 2008; Freitas et al., 2009; Basso et al., 2012).

Os rios Cuiabá e São Lourenço atravessam extensas áreas no sul do estado de Mato Grosso e são importantes tributários do Pantanal Norte, que constitui a maior planície inundável do mundo e possui fauna e flora únicas (Junk e Cunha, 2005). As bacias destes dois rios têm funções estratégicas para o estado, não só em termos ambientais, mas também econômicos, pois reúnem as três maiores cidades, com atividade agropecuária bem estabelecida e turismo em expansão.

Em Cuiabá, capital de Mato Grosso e o principal centro polarizador da bacia do rio Cuiabá, está localizado o centro comercial, industrial, político e financeiro que exerce influências socioeconômicas nas demais regiões do estado. Cuiabá conjuntamente com os municípios que formam a denominada Baixada Cuiabana - Várzea Grande, Nossa Senhora do Livramento e Santo Antônio do Leverger - apresenta uma alta taxa de antropização e incorpora $40 \%$ da produção industrial do Estado e um terço da população mato-grossense. Destaca-se nessa região o desenvolvimento da pecuária extensiva. Na região de planalto da bacia, inserida principalmente nos municípios de Chapada dos Guimarães e Campo Verde, 
predomina o plantio de soja, algodão e milho (Brasil, 2007).

$\mathrm{Na}$ bacia do rio São Lourenço, o núcleo com maior dinamismo é a cidade de Rondonópolis, onde encontram-se importantes unidades agroindustriais que fazem o beneficiamento de partes da produção agrícola da região. As paisagens do Planalto dessa região sofreram forte desmatamento para a implementação da produção de soja, milho e algodão e cana-de-açúcar utilizando técnicas modernas. Destaca-se o município de Jaciara como um dos grandes produtores de cana-de-açúcar do Estado possuindo uma usina de produção de açúcar e álcool etílico (Brasil, 2007). Nas partes centrais da bacia, mais onduladas e compostas por formações paleo-mesozoicas, predomina a pecuária e ocorrem também atividades de mineração (município de Poxoréo).

A parte baixa destas bacias, na planície alagável da parte norte do Pantanal, tem sido utilizada principalmente para criação extensiva de gado, para o turismo contemplativo e para a pesca esportiva com destaque para a vasta rede de unidades hoteleiras localizada nas margens dos rios (Shinma, 2004).

O lançamento de efluentes não tratados, bem como o escoamento superficial urbano, aparecem como fonte de metais para os recursos hídricos (Moraes e Jordão, 2002; Mil-Homens et al., 2013), e os núcleos urbanos que se localizam nas bacias do rio Cuiabá e São Lourenço, ou não possuem tratamento de efluentes domésticos, ou tratam somente uma pequena parcela do que é coletado (Zeilhofer et al., 2010).

Neste contexto, há uma grande preocupação com a qualidade da água destes mananciais para atender aos múltiplos usos da água da bacia do rio Cuiabá e São Lourenço tais como, o abastecimento público, a diluição de efluente, a geração de energia elétrica, a pesca, bem como a manutenção dos serviços ambientais promovidos pelo Pantanal, uma vez que estes rios poderão ser fontes potenciais de poluentes para esse importante e frágil ecossistema (Zeilhofer et al., 2010).

Apesar de existirem vários programas de monitoramento de qualidade de água nas bacias dos rios Cuiabá e São Lourenço sob a responsabilidade de instituições governamentais ou universidades, poucos destes programas avaliaram a presença de metais (Thomé Filho et al., 2006a; 2006b; Mato Grosso, 2005; 2006; 2010; 2014; Zeilhofer et al., 2006; Gonçalves et al., 2015; Lima et al., 2015).

O grande crescimento econômico observado na região nos últimos 40 anos, que tem como principal atividade a agropecuária, trouxe consigo grande desmatamento $\mathrm{e} o$ crescimento dos núcleos urbanos na região que são fontes potenciais de metais potencialmente tóxicos para os cursos d'água dessas bacias. A ausência de dados sobre a concentração desses metais na região e os riscos que o acúmulo pode representar para o ambiente aquático e seus usos, e ainda a importância ambiental do Pantanal Mato-grossense que funciona como grande receptor e acumulador de sedimento motivou o desenvolvimento do presente estudo. Deste modo, considera-se a hipótese de que a entrada de metais decorrente deste contexto pode vir a comprometer os usos dessas bacias no médio e longo prazo.

Assim, o presente trabalho teve por objetivo avaliar a variabilidade espacial e temporal da ocorrência e concentração de metais potencialmente tóxicos nestas bacias e sua relação com a qualidade da água, bem como discutir preliminarmente as principais fontes das potenciais contaminações.

\section{MATERIAL E MÉTODOS}

\section{1. Área de estudo}

Este estudo foi realizado na bacia hidrográfica do rio Cuiabá e do rio São Lourenço, ambos tributários do rio Paraguai (Figura 1). 


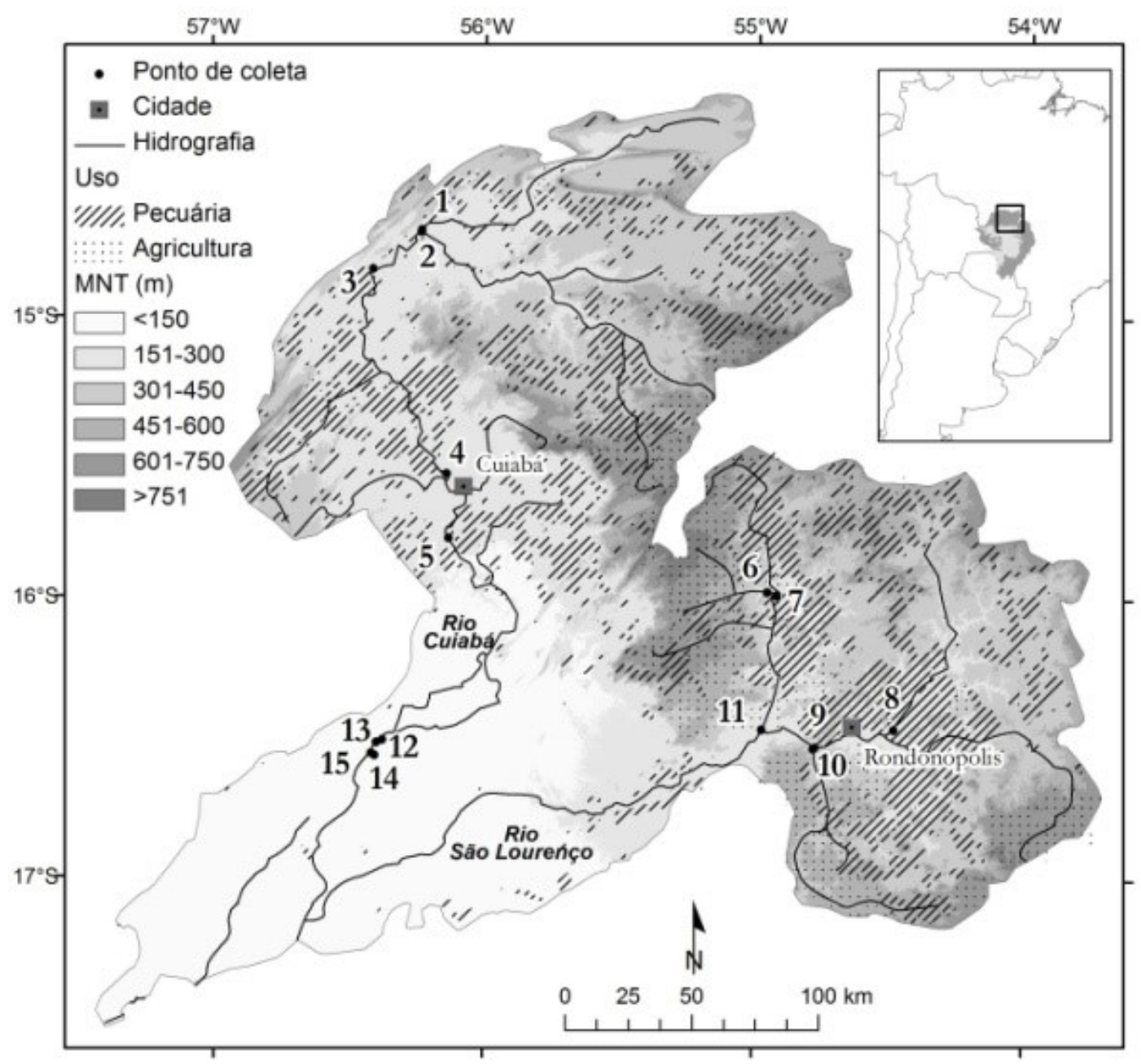

Figura 1. Localização das bacias do Rio Cuiabá e São Lourenço e dos pontos de coleta de amostras.

Fonte: Gonçalves et al. (2015).

O rio Cuiabá, que tem as suas nascentes no leste do município de Rosário Oeste, é inicialmente formado pelos cursos d'água do Cuiabá do Bonito e Cuiabá da Larga, que afloram na serra Azul em altitudes acima de $500 \mathrm{~m}$. A confluência dessas mananciais é denominado Limoeiro, local onde o rio passa a ser chamado Cuiabazinho. Quando recebe as águas do rio Manso, dobra, em média, o seu volume de água, tendo daí em diante o nome de Cuiabá. O rio São Lourenço nasce no município de Campo Verde e conflui com o rio Cuiabá dentro do Pantanal Mato-grossense. O principal afluente do rio São Lourenço é o rio Vermelho que tem a sua nascente no município de Poxoréu e atravessa a área urbana de Rondonópolis.

As bacias apresentam uma marcada sazonalidade hidroclimática, com sincronismos entre os regimes pluviométricos e hidrométricos (Gonçalves et al., 2011), com dois períodos bem definidos, um de cheia e outro de estiagem (Figura 2).

Considerando a variabilidade histórica das vazões (1966 a 2015) dos rios Cuiabá e São Lourenço, foi constatado que o ano hidrológico deste estudo (2012/2013), apresentou vazões médias de $351,60 \mathrm{~m}^{3} . \mathrm{s}^{-1}$, e de $157,67 \mathrm{~m}^{3} \cdot \mathrm{s}^{-1}$, respectivamente, portanto dentro da faixa da normalidade esperada que é de $393,60 \pm 123,10 \mathrm{~m}^{3} \cdot \mathrm{s}^{-1}$, para o rio Cuiabá, e de $149,67 \pm$ $38,36 \mathrm{~m}^{3} \cdot \mathrm{s}^{-1}$, para o rio São Lourenço (ANA, 2016). 


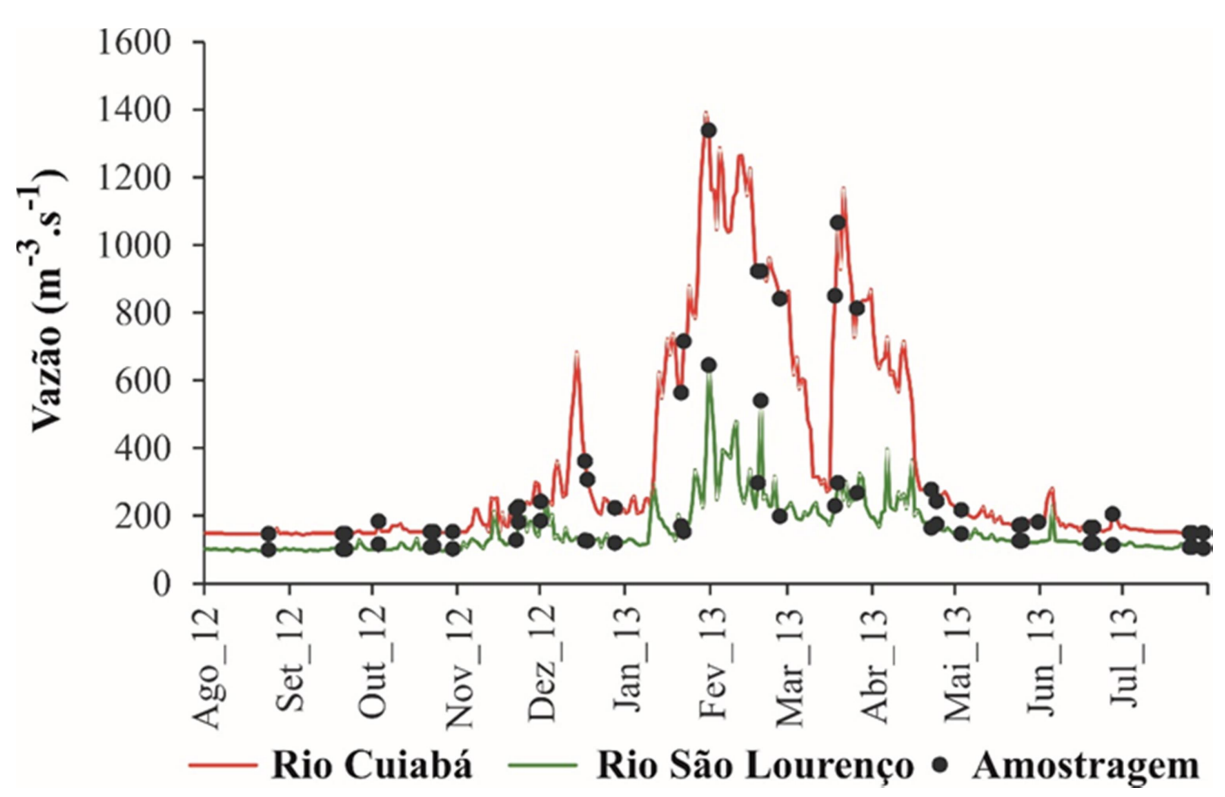

Figura 2. Vazões dos Rios Cuiabá (posto $n^{0}$ 66260001) e São Lourenço (posto $\mathrm{n}^{\circ} 66460000$ ) ao longo do período de estudo, identificando as datas de amostragem.

\subsection{Amostragem}

Com o objetivo de verificar a variação espacial da concentração de metais potencialmente tóxicos nas bacias dos rios Cuiabá e São Lourenço, foram escolhidos 15 pontos de coleta estrategicamente localizados considerando as diferentes características geomorfológicas, assim como o uso e ocupação do solo (Figura 1).

Foram coletadas mensalmente, no período compreendido entre agosto/2012 a julho/2013, amostras de água superficial em 15 pontos de amostragem e de sedimento de leito em 9 dos 15 pontos pré-estabelecidos (CB3, CB5, SL6, SL10, SL11, CB12, CB13, CB14 e CB15). Os pontos indicados na Figura 1 foram identificados por sigla (CB e SL) dependendo de sua localização na bacia rio Cuiabá e São Lourenço, respectivamente. Dentre os pontos de coleta, CB1 e SL6 a SL11 apresentam características de rio de planalto, os pontos CB2 a CB4 correspondem ao curso médio do Rio Cuiabá e os pontos CB5, CB12 a CB15 apresentam característica de rio de planície.

As amostras de águas superficiais em cada ponto foram coletadas manualmente em três posições da seção transversal do rio (próximo à margem direita, no meio do rio e perto da margem esquerda, correspondendo a aproximadamente 25,50 e $75 \%$ da largura do rio). Em seguida estas amostras foram misturadas e homogeneizadas formando uma amostra composta. Uma alíquota de $300 \mathrm{~mL}$ foi transferida para um frasco de polietileno de capacidade de 500 $\mathrm{mL}$, no qual foi feito, no momento da coleta, o ajuste do $\mathrm{pH}$ com adição de ácido nítrico concentrado até $\mathrm{pH}$ 2,0 para posterior análise de metais. Os materiais utilizados na coleta da amostra foram previamente enxaguados (uma vez) com a própria amostra de água superficial no momento da coleta.

No campo foram medidos os parâmetros físico-químicos da água - $\mathrm{pH}$, condutividade elétrica (CE), oxigênio dissolvido (OD), temperatura da água - após calibração dos equipamentos multiparâmetros (marca $\mathrm{HACH}$, modelo HQ40d multi e WTW, modelo pH340). Os valores foram registrados após a estabilização dos mesmos. Para a determinação do DBO, utilizou-se frasco âmbar e incubação por período de 5 dias. A turbidez também foi determinada em campo usando turbidímetro Tecnopon TB-1000P.

As amostras de água coletadas foram armazenadas em caixas térmicas sob gelo até a 
chegada ao laboratório, onde foram acondicionadas em refrigeradores com temperatura entre 4 e $10^{\circ} \mathrm{C}$.

A amostragem de sedimento de leito foi realizada sob a lâmina d'água utilizando-se uma draga de Petersen. As amostras de sedimento foram retiradas das áreas de curva convexas do rio, onde os sedimentos tendem a se depositar. A quantidade de amostras de sedimento de leito foi de aproximadamente $1,0 \mathrm{~kg}$. As amostras foram armazenadas em sacos plásticos etiquetados e mantidas em caixas térmicas sob resfriamento com gelo até a chegada em laboratório onde foram armazenadas em freezer à temperatura aproximada de $-20^{\circ} \mathrm{C}$ até $\mathrm{o}$ momento da análise.

\subsection{Determinação da concentração dos metais potencialmente tóxicos}

\subsubsection{Determinação nas amostras de águas}

As amostras de águas não filtradas foram previamente submetidas a uma digestão com ácido nítrico conforme descrito no Método $3030 \mathrm{D}$ do Standard Methods for the Examination of Water and Wastewater (APHA, 2012). A concentração total de $\mathrm{Cr}, \mathrm{Cu}, \mathrm{Fe}, \mathrm{Mn}, \mathrm{Pb}$ e $\mathrm{Zn}$ (expressa em $\mathrm{mg} \mathrm{L}^{-1}$ de peso seco) foi determinada por espectrometria de emissão ótica com plasma indutivamente acoplado (ICP OES) com nebulizador tipo "seaspray", modelo 720 Agilent ${ }^{\circledR}$.

O ICP OES foi operado em potência de radiofrequência de $1,10 \mathrm{~kW}$, fluxo de argônio do plasma de 15,0 L min ${ }^{-1}$ e pressão do nebulizador de $200 \mathrm{kPa}$. Foram utilizadas soluções padrão estoque multielementares de $\mathrm{Cr}, \mathrm{Cu}, \mathrm{Fe}, \mathrm{Mn}, \mathrm{Pb}$ e $\mathrm{Zn}$ de $1000 \mathrm{mg} \mathrm{L}^{-1}$ da marca Specsol $^{\circledR}$. As soluções de trabalho foram preparadas por diluições em ácido nítrico $5 \%$ (v:v). As determinações foram feitas em triplicata, por padronização externa.

\subsubsection{Determinação nas amostras de sedimento}

As amostras de sedimento foram secas ao ar antes da análise, e a umidade residual foi determinada por aquecimento em estufa a $105^{\circ} \mathrm{C}$ e os resultados foram expressos em mg kg-1 de peso seco. As amostras integrais de sedimento de leito secas ao ar foram tratadas de acordo com o método 3050B USEPA (2011) que consiste na digestão ácida usando ácido nítrico, seguida da oxidação com peróxido de hidrogênio, finalizando a digestão com ácido clorídrico.

A concentração total de $\mathrm{Cr}, \mathrm{Cu}, \mathrm{Fe}, \mathrm{Mn}, \mathrm{Pb}$ e $\mathrm{Zn}$ foi determinada em espectrômetro de absorção atômica com atomizador em chama (FAAS), marca Varian (modelo-Spectra AA-220). Para a determinação de metais em sedimentos de leito por FAAS foi utilizada a chama ar-acetileno. Foram utilizados os padrões de $\mathrm{Cr}, \mathrm{Cu}, \mathrm{Fe}, \mathrm{Mn}, \mathrm{Pb}$ e $\mathrm{Zn}$ de $1000 \mathrm{mg} \mathrm{L}^{-1}$ para AAS da marca Specsol ${ }^{\circledR}$. As soluções de trabalho foram preparadas a partir de diluições sucessivas das soluções estoque com ácido nítrico a $1 \%$ (v:v).

\subsubsection{Determinação dos limites de detecção e de quantificação dos métodos}

Os limites de deteç̧ão (LD) e quantificação (LQ) foram calculados de acordo com Thompson e Ellison (2002). Para a determinação de LD e LQ, foram feitas 10 leituras com o padrão de menor concentração, sendo feita a leitura alternada durante o procedimento.

\subsubsection{Análise dos resultados}

Para a montagem de uma matriz espaço-temporal dos dados analíticos para as análises estatísticas, primeiramente foi calculada a média das triplicatas para cada variável. Os valores abaixo do limite de detecção (LD) foram considerados insignificantes e substituídos por zero. Os valores acima do LD e inferiores ao limite de quantificação (LQ) foram substituídos pelo valor médio entre o LD e o LQ. Dessa forma, foi definido o limiar de separação para a presença ou ausência de um determinado metal, visto que esse tipo de variável apresenta 
elevada quantidade de dados censurados (ou seja, resultados inferiores ao LD, isto é, o menor nível de concentração que pode ser determinado como estatisticamente diferente de uma amostra em branco). Este procedimento é uma adaptação do método clássico, utilizado em diversas pesquisas (Chen et al., 2007; Felipe-Sotelo et al., 2007; Terrado et al., 2009).

Em seguida, foi calculada a frequência de detecção (FD) e a concentração média ponderada (Conc) de cada metal. A FD correspondeu ao número de vezes que o valor do metal foi maior ao LD, dividido pelo número total de amostras. Já a "Conc" corresponde à somatória das concentrações quando seu valor foi maior que o $\mathrm{LD}$, dividido pelo número de vezes que a concentração foi maior que o LD. Este procedimento foi repetido para sintetizar o padrão espacial, onde os meses de amostragem foram as réplicas, enquanto para o padrão temporal, os pontos de amostragem foram as réplicas. $\mathrm{O}$ intuito dessas transformações foi reduzir o número de dados censurados e a possibilidade de dados com distribuição não-normal.

Para avaliar a relação dos metais entre si e com a qualidade da água, foram feitas análises de correlações de Spearman, com os valores das concentrações maiores que o LD. Por isso, o número de amostras consideradas para cada correlação foi variável. Este procedimento foi realizado para as concentrações de metais na água superficial e sedimento de leito. O nível de significância estatística (p) adotado, foi menor ou igual a 0,05 e as análises foram realizadas no programa STATISTICA ${ }^{\circledR}$, versão 7.0.

\section{RESULTADOS E DISCUSSÃO}

Nas amostras de água, os metais detectados com maior frequência foram $\mathrm{Fe}, \mathrm{Zn}$ e $\mathrm{Mn}$ seguidos do $\mathrm{Cr}, \mathrm{Pb}$ e $\mathrm{Cu}$, refletindo a composição geoquímica dos solos (latossolos) predominantes na região de estudo (Ker, 1997; Chiaranda et al., 2016). Por outro lado, Coringa et al. (2014) verificaram que o cromo foi detectado somente em alguns solos do Pantanal, enquanto o $\mathrm{Cu}$ foi detectado somente em alguns horizontes de poucos perfis. Os elementos $\mathrm{Mn}$ e Fe foram os que apresentaram maior porcentagem de valores acima do VMP (Tabela 1), no entanto não indicam uma poluição, uma vez que refletem a geoquímica da área de estudo. Não foram encontrados estudos que reportem a presença de rochas ricas em $\mathrm{Pb}$ na bacia do Rio Cuiabá, no entanto alguns estudos na região sudoeste de Mato Grosso reportam a ocorrência eventual de galena associada a depósitos de ouro (Geraldes et al., 1996; Rosa et al., 2003). Estes comportamentos foram observados em estudo anterior realizado nos mesmos pontos no período compreendido entre agosto de 2011 e julho de 2012 (Gonçalves et al., 2015).

Também no sedimento, os elementos $\mathrm{Fe}$ e $\mathrm{Mn}$ foram os que ocorreram em maiores concentrações e com maior frequência. Este fato relaciona-se com a composição do solo da região, que é rico em óxidos de Fe e Mn e também em Zn (Fadigas et al., 2002; Coringa et al., 2014) representando uma influência claramente geogénica. Por outro lado, os elementos $\mathrm{Pb}$ e $\mathrm{Cr}$ foram também detectados com elevada frequência no sedimento. Da análise dos resultados, destaca-se o $\mathrm{Pb}$ que apresentou concentrações acima do limite sugerido por MacDonald et al. (2000) em 4,6\% das amostras, apontando para um potencial risco para os organismos aquáticos. Os limites sugeridos por aqueles autores representam a concentração abaixo da qual não se espera que ocorram efeitos tóxicos para os organismos que vivem no sedimento. 
Tabela 1. Porcentagem de deteç̧ão dos metais analisados nas matrizes água e sedimento e porcentagem de amostras em desacordo com a legislação e os limites estabelecidos pela resolução do Conselho Nacional de Meio Ambiente para as concentrações de metais em água e recomendados por MacDonald et al. (2000) para sedimento de leito.

\begin{tabular}{|c|c|c|c|c|c|c|c|c|c|c|}
\hline \multicolumn{6}{|c|}{ Água } & \multicolumn{5}{|c|}{ Sedimento } \\
\hline \multirow{2}{*}{ Metal } & \multirow{2}{*}{$\mathrm{FD}^{(\mathrm{a})}$} & \multirow{2}{*}{$\begin{array}{c}\%> \\
\text { VMP }^{(b)}\end{array}$} & \multirow{2}{*}{$\begin{array}{c}\text { CONAMA } \\
357 / 05 \\
\left(\mathrm{mg} \mathrm{L}^{-1}\right)\end{array}$} & \multicolumn{2}{|c|}{ LD } & \multirow{2}{*}{ FD } & \multirow{2}{*}{$\begin{array}{c}\%> \\
\text { TEC (c) }^{(\text {c) }}\end{array}$} & \multirow{2}{*}{$\begin{array}{c}\mathrm{TEC}^{(\mathrm{d})} \\
\left(\mathrm{mg} \mathrm{kg}^{-1}\right)\end{array}$} & $\mathrm{LD}$ & LQ \\
\hline & & & & & $\mathrm{mg} \mathrm{L}^{-1}$ & & & & \multicolumn{2}{|c|}{$\mathrm{mg} \mathrm{kg}^{-1}$} \\
\hline $\mathrm{Cr}$ & 28,5 & 2,30 & 0,10 & 0,002 & 0,010 & 63,8 & 2,78 & 31,6 & 0,39 & 1,20 \\
\hline $\mathrm{Cu}$ & 7,10 & $7,10^{(\mathrm{e})}$ & 0,01 & 0,004 & 0,011 & 23,1 & - & 31,6 & 0,25 & 0,75 \\
\hline $\mathrm{Fe}$ & 98,2 & 91,0 & 0,18 & 0,040 & 0,13 & 100 & - & - & 1,27 & 3,87 \\
\hline Mn & 69,6 & $69,6^{(\mathrm{f})}$ & 0,05 & 0,050 & 0,20 & 89,8 & - & - & 0,25 & 0,77 \\
\hline $\mathrm{Pb}$ & 22,0 & $0,590^{(\mathrm{e})}$ & 0,009 & 0,002 & 0,010 & 75,9 & 16,7 & 35,8 & 5,82 & 17,6 \\
\hline $\mathrm{Zn}$ & 73,8 & 4,1 & 0,3 & 0,004 & 0,013 & 48,1 & - & 121 & 0,13 & 0,38 \\
\hline
\end{tabular}

Nota: ${ }^{(a)}$ FD - frequência de detecção;

(b) $\%>$ VMP $=$ porcentagem de amostras de água que apresentaram concentrações acima do valor máximo permitido pela resolução CONAMA 357/2005 (Brasil, 2005);

(c) $\%>$ TEC $=$ porcentagem de amostras de sedimento que apresentaram concentrações dos metais superiores aos limites recomendados por MacDonald et al. (2000);

(d) Consensus based TEC (threshold effect concentration) - concentração abaixo da qual não se espera que ocorram efeitos tóxicos para os organismos que vivem no sedimento;

(e) Devido ao valor de $\mathrm{LQ}$ do $\mathrm{Cu}$ e do $\mathrm{Pb}$ ligeiramente superior ao limite máximo estabelecido na resolução CONAMA 357/2005 essa proporção pode estar subestimada;

(f) Uma vez que o LD do Mn é igual ao limite da resolução CONAMA 357/2005, considerou-se que qualquer valor detectado, mesmo que não quantificado, supera a legislação.

Em relação à variação espacial, registaram-se as maiores concentrações de Fe e Mn nas amostras de água recolhidas nos pontos mais altos da bacia do Rio São Lourenço e no braço do Rio Vermelho (SL8, SL9). Nestes locais predominam atividades agropecuárias e atividades de mineração de diamante (região de Poxoréu) que podem intensificar os processos erosivos com carreamento de material particulado enriquecido nestes metais para dentro do curso d'água (Núñez et al., 1999; Panachuki et al., 2006; Viana et al., 2011). Em contrapartida, no sedimento de leito não foram observadas diferenças entre os pontos de coleta, com exceção dos pontos SL6 (Córrego Tenente Amaral) e SL10 (Córrego Ponte de Pedra) que apresentaram as menores concentrações desses dois metais (Figura 3).

Apesar de ocorrer em menores concentrações do que o Fe e Mn, o Zn é também um metal abundante (Fadigas et al., 2002) nos solos da região da bacia e foi detectado em elevada frequência. Entretanto, não se observou a existência de uma tendência espacial para o zinco.

As concentrações de $\mathrm{Cu}$ em sedimento e água foram similares ao longo da bacia, destacando somente o ponto SL8 no qual a concentração em água foi mais elevada. Esse ponto corresponde ao rio Vermelho a montante da região urbana de Rondonópolis, que atravessa áreas com ocupação essencialmente agrícola na qual ocorre uso intenso de agrotóxicos, muitos deles compostos de cobre.

Os metais mais tóxicos dentre os estudados, $\mathrm{Pb}$ e $\mathrm{Cr}$, também ocorreram com elevada frequência nas amostras de sedimento apresentando alguns resultados acima dos limites recomendados por MacDonald et al. (2000), limites estes que foram propostos como o nível toxicologicamente seguro para organismos que residem no sedimento (Tabela 1). $\mathrm{O} \mathrm{Pb}$ ocorreu em concentrações acima deste limite em $16,7 \%$ das amostras representando uma 
maior probabilidade de efeitos adversos à biota.

a)

c)
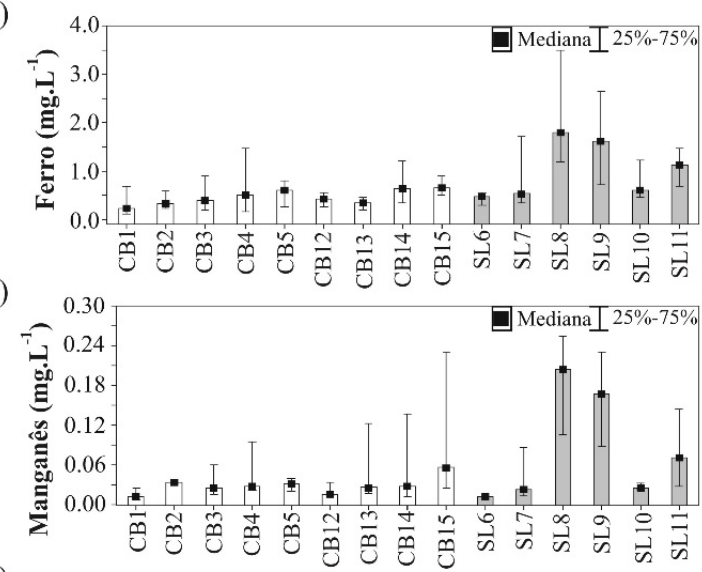

e)

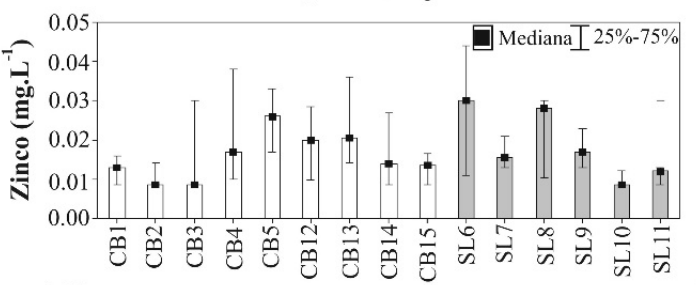

g)

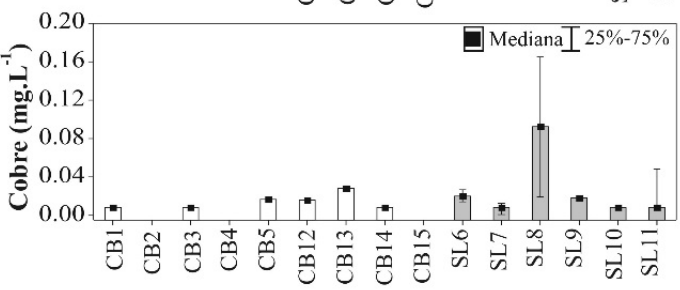

i)

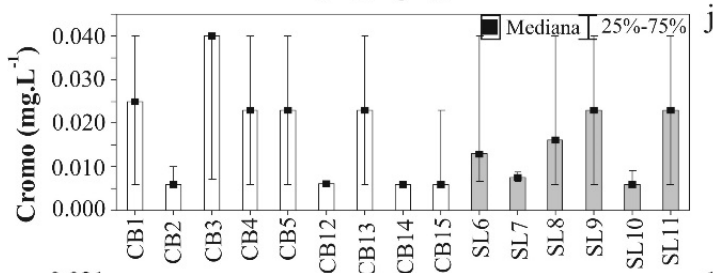

k)

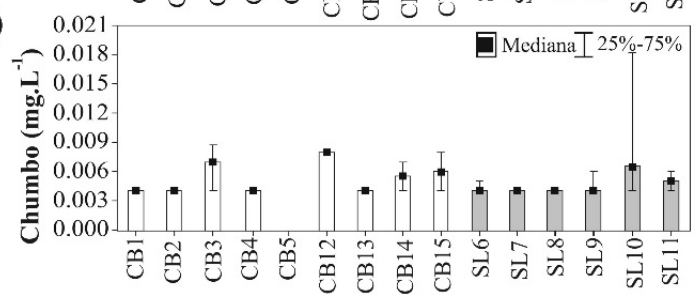

b)

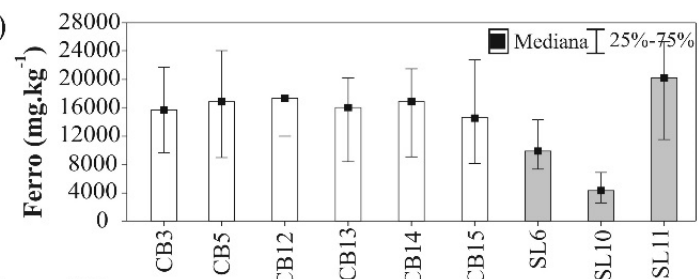

d)

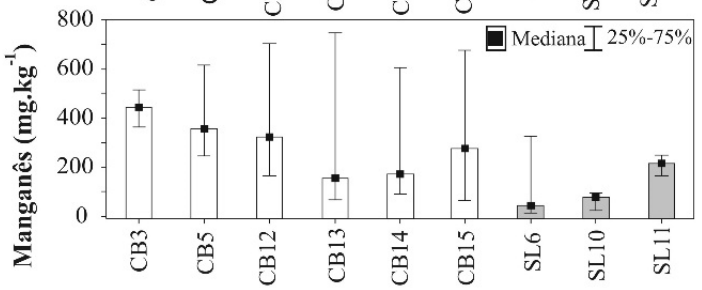

f)

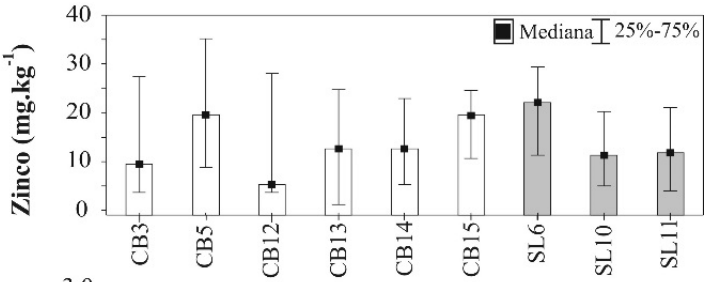

h)
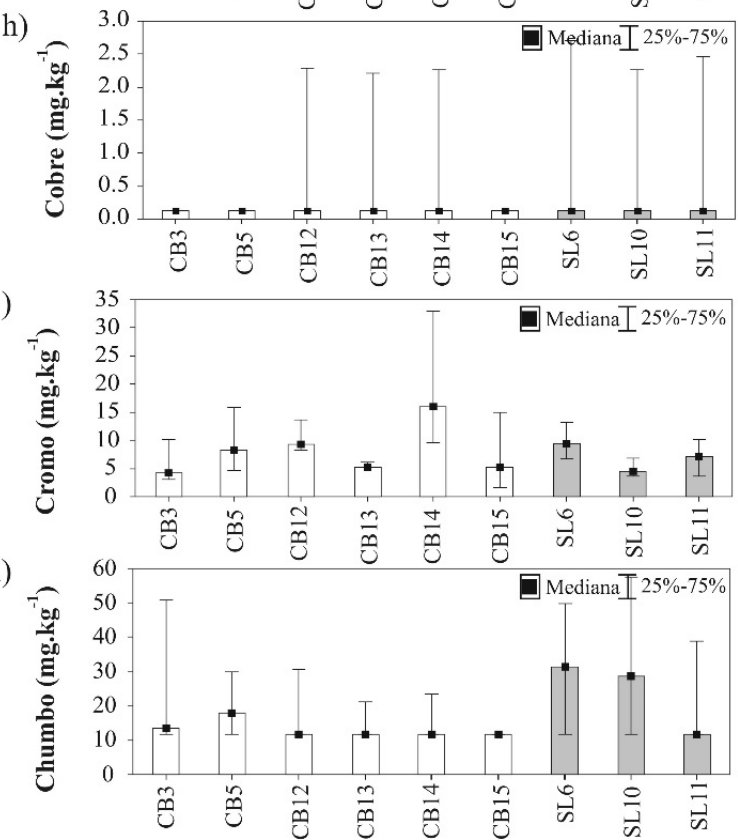

Figura 3. Variação espacial das concentrações dos metais nas amostras de água (gráficos a, c, e, g, $\mathrm{i}, \mathrm{k}$ ) e de sedimento de leito (gráficos b, d, f, h, j, l) dos rios Cuiabá (CB) e São Lourenço (SL) para o período compreendido entre agosto de 2012 e julho de 2013.

$\mathrm{O} \mathrm{Pb}$ ocorre naturalmente em diversos minerais, mas suas concentrações em água são geralmente baixas devido à baixa solubilidade de suas rochas, conforme revisado por Bosso e Enzweiler (2008). No entanto, também pode haver contribuição de atividades humanas aumentando as suas concentrações. Este elemento é intensamente usado na indústria de baterias, ocorre como contaminante em fertilizantes e é usado como componente de pesticidas (Ramalho et al., 2000). Nas amostras de sedimento, o Pb ocorreu em concentrações mais elevadas nas regiões mais altas da bacia (planalto na bacia do Rio São Lourenço e no curso 
médio do rio Cuiabá), sendo que as fontes antropogênicas - uso de fertilizantes, escoamento superficial urbano - figuram como a causa mais provável para a ocorrência deste elemento nos sedimentos (Figuras 3 e 4). Por outro lado, as concentrações de $\mathrm{Cr}$ apresentaram uma variação mais heterogênea ao longo da bacia, não sendo possível identificar nenhuma tendência espacial.

a)

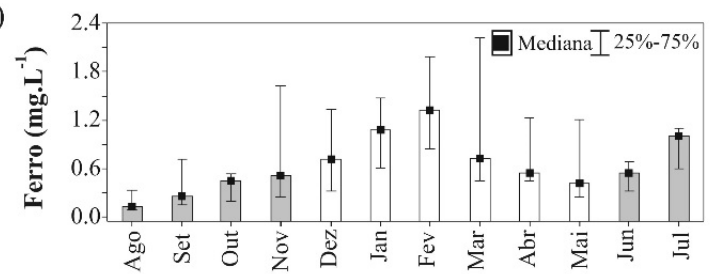

c)

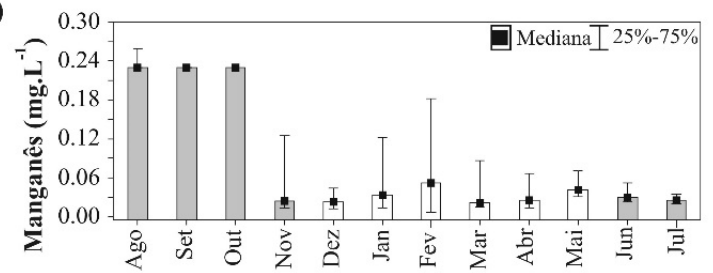

e)

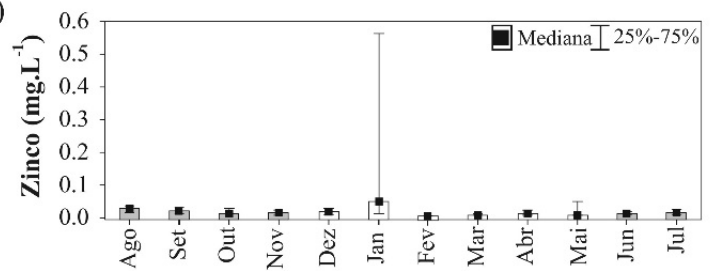

g)

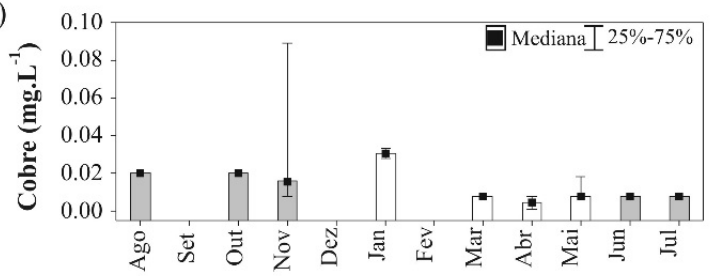

i)

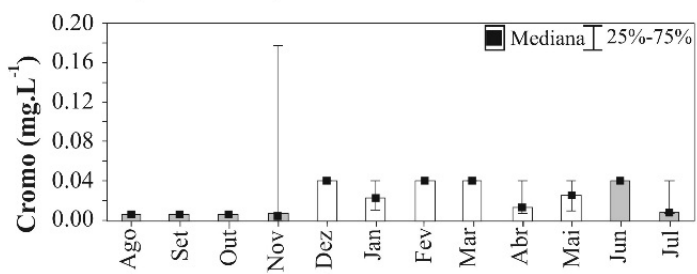

$\mathrm{k})$

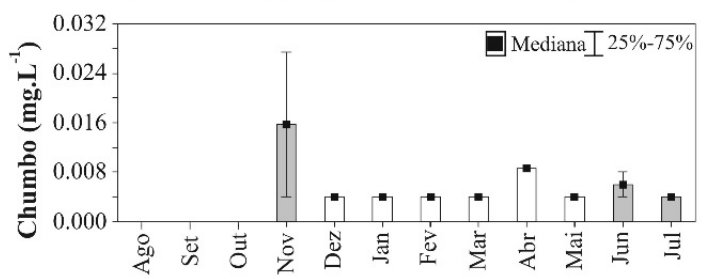

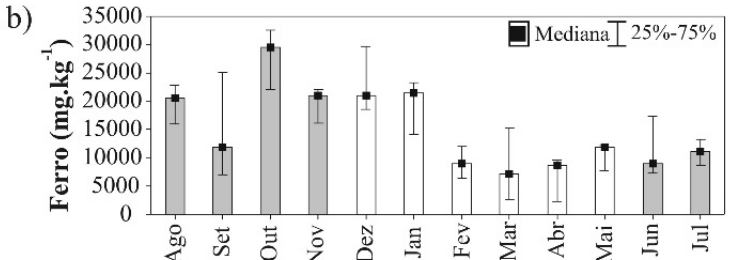

d)
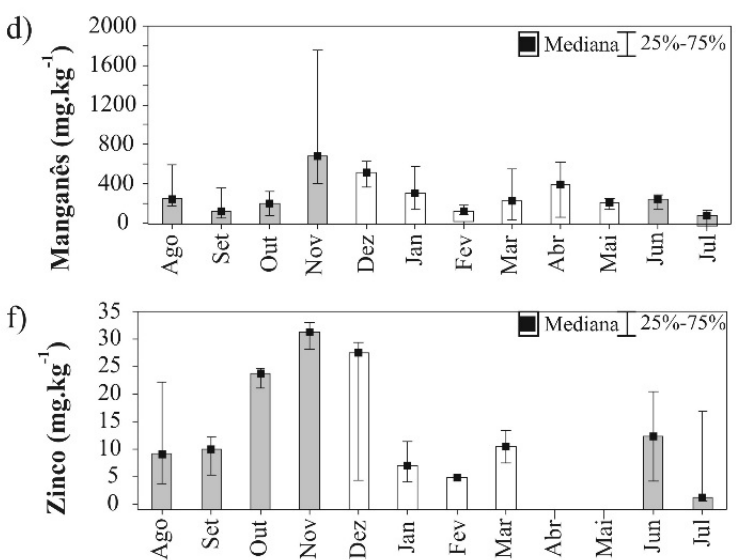

h)

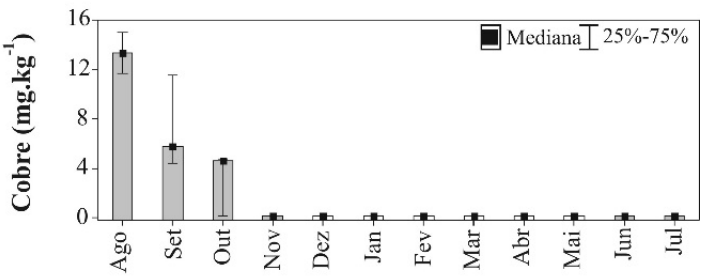

j)

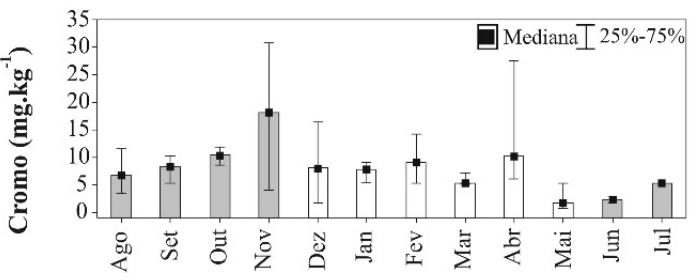

1)

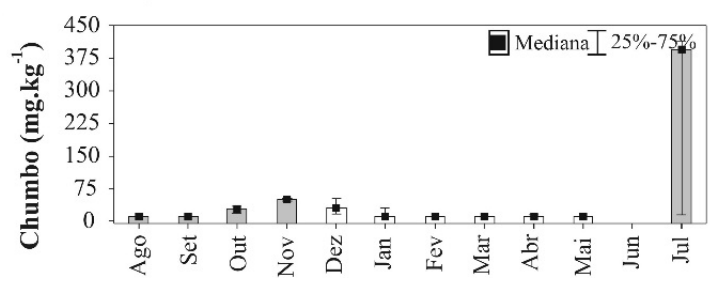

Figura 4. Variação temporal das concentrações dos metais nas amostras de água (gráficos a, c, e, $\mathrm{g}, \mathrm{i}, \mathrm{k}$ ) e de sedimento de leito (gráficos $\mathrm{b}, \mathrm{d}, \mathrm{f}, \mathrm{h}, \mathrm{j}, \mathrm{l}$ ) dos rios Cuiabá e São Lourenço para o período compreendido entre agosto de 2012 e julho de 2013. Barras cinza correspondem aos meses de maior pluviosidade no período.

Considerando a variação temporal ao longo do período de coleta, observou-se uma tendência para a ocorrência das maiores concentrações de $\mathrm{Fe}, \mathrm{Mn}, \mathrm{Zn}$ e $\mathrm{Cr}$ no sedimento de 
leito no início do período das chuvas. Entretanto, a mesma tendência não foi observada para os referidos metais nas amostras de água. No caso das concentrações de Fe nas amostras de água, houve uma tendência de aumento nos meses de maior vazão, mas o mesmo não foi observado para o $\mathrm{Mn}$. Para as concentrações de $\mathrm{Cu}$ e $\mathrm{Pb}$, nenhuma tendência temporal foi observada nas duas matrizes analisadas. Alguns trabalhos têm reportado tendência de aumento nas concentrações de metais em água em períodos chuvosos, como o estudo de Rietzler et al. (2001) em um afluente do reservatório da Pampulha em Belo Horizonte (MG), região intensamente ocupada com núcleo urbano e com indústrias de ferro e aço, solventes e tintas e construção civil.

Entretanto, efeitos contrários influenciam fortemente a concentração dos metais na água dependendo da pluviosidade. Ao mesmo tempo em que o escoamento superficial, e consequente carreamento dos metais para os corpos d'água, é mais intenso no período chuvoso, há o aumento da vazão que contribui para a diluição dos mesmos. Destaca-se ainda que o escoamento superficial pelas águas de chuva normalmente leva a picos de concentração de contaminantes após eventos de intensa precipitação que podem não ser detectados quando se utiliza esquema de amostragem pontual em datas pré-programadas, como foi o caso do presente estudo (Bian et al., 2011; Laabs et al., 2002).

Estudo anterior, desenvolvido por Sampaio (2003) na bacia do Alto Paraguai, no qual foram coletadas amostras principalmente em área de planície de inundação, incluiu um ponto de amostragem no rio Cuiabá, próximos aos pontos CB13, CB14 e CB15 desta pesquisa, e um ponto no rio Vermelho, próximo do ponto SL9. Comparando os resultados, observou-se que, com exceção do $\mathrm{Pb}$, as faixas de concentração em amostras de água determinadas por aquele autor se assemelharam às do presente estudo. Por outro lado, nas amostras de sedimento, as concentrações de $\mathrm{Fe}, \mathrm{Mn}$ e $\mathrm{Pb}$ foram aproximadamente 10 vezes superiores às determinadas por aquele autor, enquanto as concentrações de $\mathrm{Zn}$ e $\mathrm{Cr}$ foram muito semelhantes. As diferenças observadas para o $\mathrm{Fe}, \mathrm{Mn}$ e $\mathrm{Pb}$ devem-se provavelmente ao fato do estudo realizado por Sampaio ter ocorrido em 2003, ou seja, ter sido desenvolvido há mais de dez anos, refletindo, provavelmente, nos resultados do presente estudo, a influência da ocupação mais intensa nos anos seguintes. Estudos futuros devem investigar se essa hipótese se confirma.

O estudo realizado pelo Sistema de Informação Geoambiental de Cuiabá, Várzea Grande e Entorno - SIG CUIABÁ (Thomé Filho et al., 2006a; 2006b) avaliou a concentração de metais em águas de córregos da região em 105 pontos. Os resultados do estudo mostraram que as concentrações de $\mathrm{Fe}$ e $\mathrm{Mn}$ atingiram 3,173 e 2,548 $\mathrm{mg} \mathrm{L}^{-1}$, respectivamente, valores estes superiores aos encontrados no rio Cuiabá no presente estudo. Estes resultados podem ser explicados provavelmente pelo fato de se tratarem de córregos de baixa vazão, localizados em área urbana, e que quando submetidos aos fortes impactos dos lançamentos de descargas urbanas ou industriais sofrem um maior impacto do que rios de elevada vazão. Também os elementos $\mathrm{Cu}, \mathrm{Pb}$ e $\mathrm{Cr}$ foram detectados em concentrações superiores aos estabelecidos pela legislação nos córregos urbanos e atingiram valores superiores aos detectados no Rio Cuiabá.

A Tabela 2 apresenta as correlações que se mostraram significativas para as seguintes variáveis: i) concentrações dos metais em sedimento entre si, ii) concentrações dos metais em água entre si; iii) concentrações dos metais em água com as variáveis físicas e químicas da água e iv) concentração dos metais em sedimento com turbidez na água.

A correlação da concentração de $\mathrm{Fe}, \mathrm{Mn}$ e $\mathrm{Cu}$ na água com a turbidez indica que esses metais estão sendo transportados no particulado fino em suspensão na água. Por outro lado, a correlação positiva da turbidez com Fe e Mn no sedimento é uma indicação de que o material que está sendo transportado em suspensão na água precipita incorporando-se ao sedimento. Considerando que $\mathrm{Fe}$ e $\mathrm{Mn}$ são dois dos principais constituintes do solo e que estão correlacionados entre si nas duas matrizes (água e sedimento), a erosão na área da bacia vem 
contribuindo para a elevada presença desses metais na água e sedimento. Observou-se também a existência de uma correlação positiva da DBO e negativa do OD com as concentrações de $\mathrm{Fe}$ e $\mathrm{Mn}$ na água o que pode sugerir que esses metais estão também associados à matéria orgânica presente no rio Cuiabá.

Tabela 2. Matriz de correlação entre os metais em mesma matriz e com as variáveis físicas e químicas da água superficial.

\begin{tabular}{|c|c|c|c|c|c|c|c|}
\hline \multirow{2}{*}{ Metais } & \multirow{2}{*}{ Correlações } & \multicolumn{2}{|c|}{ Água Superficial } & \multirow[b]{2}{*}{$\mathrm{Cr}$} & \multirow[b]{2}{*}{$\mathbf{F e}$} & \multirow[b]{2}{*}{ Mn } & \multirow[b]{2}{*}{$\mathbf{Z n}$} \\
\hline & & $\mathbf{C u}$ & $\mathbf{P b}$ & & & & \\
\hline \multirow{2}{*}{$\mathbf{P b}$} & $\mathrm{r}$ & 0,36 & & & & & \\
\hline & $\mathrm{N}$ & 6 & & & & & \\
\hline \multirow{2}{*}{$\mathrm{Cr}$} & $\mathrm{r}$ & 0,18 & --- & & & & \\
\hline & $\mathrm{N}$ & 10 & & & & & \\
\hline \multirow{2}{*}{$\mathbf{F e}$} & $\mathrm{r}$ & 0,35 & $-0,30$ & 0,46 & & & \\
\hline & $\mathrm{N}$ & 23 & 38 & 64 & & & \\
\hline \multirow{2}{*}{ Mn } & $\mathrm{r}$ & 0,30 & $-0,20$ & $-0,15$ & 0,62 & & \\
\hline & $\mathrm{N}$ & 21 & 38 & 43 & 131 & & \\
\hline \multirow{2}{*}{ Zn } & $\mathrm{r}$ & $\mathbf{0 , 5 3}$ & 0,17 & $-0,41$ & $-0,18$ & 0,10 & \\
\hline & $\mathrm{N}$ & 17 & 32 & 48 & 123 & 131 & \\
\hline \multirow{2}{*}{ Turb. } & $\mathrm{r}$ & 0,49 & $-0,28$ & 0,14 & 0,45 & 0,40 & 0,05 \\
\hline & $\mathrm{N}$ & 23 & 38 & 64 & 165 & 131 & 124 \\
\hline \multirow{2}{*}{ pH } & $\mathrm{r}$ & $-0,28$ & $-0,07$ & 0,02 & $-0,22$ & $-0,08$ & 0,01 \\
\hline & $\mathrm{N}$ & 23 & 38 & 64 & 165 & 131 & 124 \\
\hline \multirow{2}{*}{ Cond. } & $\mathrm{r}$ & $-0,18$ & 0,01 & $-0,01$ & $-0,15$ & 0,02 & 0,06 \\
\hline & $\mathrm{N}$ & 23 & 38 & 64 & 165 & 131 & 124 \\
\hline \multirow{2}{*}{ OD } & $\mathrm{r}$ & $-0,24$ & 0,09 & 0,12 & $-0,11$ & $-0,14$ & $-0,02$ \\
\hline & $\mathrm{N}$ & 23 & 38 & 64 & 165 & 131 & 124 \\
\hline \multirow{2}{*}{ DBO } & $\mathrm{r}$ & 0,24 & $-0,08$ & 0,18 & 0,31 & 0,34 & 0,01 \\
\hline & $\mathrm{N}$ & 23 & 38 & 64 & 165 & 131 & 124 \\
\hline \multirow{2}{*}{ Metais } & \multirow{2}{*}{ Correlações } & \multicolumn{2}{|c|}{ Sedimento de fund } & & & & \\
\hline & & $\mathrm{Cu}$ & $\mathbf{P b}$ & $\mathrm{Cr}$ & $\mathbf{F e}$ & Mn & Zn \\
\hline \multirow{2}{*}{$\mathbf{P b}$} & $\mathrm{r}$ & 0,20 & & & & & \\
\hline & $\mathrm{N}$ & 71 & & & & & \\
\hline \multirow{2}{*}{$\mathrm{Cr}$} & $\mathrm{r}$ & 0,12 & $\mathbf{0 , 3 1}$ & & & & \\
\hline & $\mathrm{N}$ & 73 & 53 & & & & \\
\hline \multirow{2}{*}{$\mathbf{F e}$} & $\mathrm{r}$ & 0,28 & 0,05 & 0,26 & & & \\
\hline & $\mathrm{N}$ & 108 & 71 & 73 & & & \\
\hline \multirow{2}{*}{ Mn } & $\mathrm{r}$ & 0,02 & 0,21 & 0,19 & 0,36 & & \\
\hline & $\mathrm{N}$ & 103 & 69 & 72 & 103 & & \\
\hline \multirow{2}{*}{ Zn } & $\mathrm{r}$ & 0,27 & $\mathbf{0 , 5 5}$ & $\mathbf{0 , 4 3}$ & 0,21 & 0,27 & \\
\hline & $\mathrm{N}$ & 53 & 40 & 42 & 53 & 52 & \\
\hline \multirow{2}{*}{ Turb } & $\mathrm{r}$ & 0,12 & 0,03 & $-0,03$ & 0,28 & 0,22 & 0,20 \\
\hline & $\mathrm{N}$ & 108 & 71 & 73 & 108 & 103 & 53 \\
\hline
\end{tabular}

Legenda: $r=$ coeficiente de correlação de Spearman; $\mathrm{N}=$ número de amostras; negrito = valores com significância $\leq 0.05$. 
De uma maneira geral, os metais tendem a precipitar como hidróxidos em faixas de $\mathrm{pH}$ alcalinos. A solubilidade do $\mathrm{Zn}$, por exemplo, decresce com o aumento do $\mathrm{pH}$ na faixa entre 4 e 9 (Lenzi et al., 2011). Uma vez que a presença dos metais no sedimento não depende somente da solubilidade, mas também das fontes e formas de entrada no ambiente e da sua ocorrência natural, essa correlação não foi observada para a maioria dos metais, com exceção do $\mathrm{Mn}$ no sedimento que apresentou correlação positiva com o $\mathrm{pH}$ da água, enquanto $\mathrm{Fe}$ em água e $\mathrm{Pb}$ em sedimento apresentaram correlação negativa. A correlação negativa do $\mathrm{Fe} e m$ água com o $\mathrm{pH}$ seria esperada considerando sua tendência de precipitar como hidróxido de ferro em condições mais alcalinas (Minella e Merten, 2006). Em contrapartida, as fontes de cromo e chumbo não são normalmente contínuas e as variações de suas concentrações não podem ser explicadas somente pelo $\mathrm{pH}$.

As correlações positivas entre $\mathrm{Cu}$ e $\mathrm{Zn}$ em água e em sedimento apontam para fontes semelhantes destes metais que estão muitas vezes associadas a pesticidas e dejetos de criações de animais (Santos et al., 2013). Dada a grande extensão da bacia estudada, o esquema mensal de amostragem, a heterogeneidade do uso e ocupação em sua área e ainda as características de planalto e planície, além das diferentes formações geológicas ao longo da bacia, algumas relações não são facilmente explicadas.

\section{CONCLUSÕES}

Este trabalho mostrou que a ocorrência dos metais na água e no sedimento de fundo apresentaram diferenças quanto a frequência de ocorrência, uma vez que a frequência de detecção dos metais no sedimento é 35\% maior que na água, e na ordem da ocorrência, já que os metais $\mathrm{Zn}, \mathrm{Mn}, \mathrm{Cr}$ e $\mathrm{Pb}$ mudaram sua ordem de importância entre as matrizes de origem. Essas diferenças observadas podem ser atribuídas a representatividade temporal da matriz analisada, pois os metais presentes na água são um retrato instantâneo dos aportes ocorridos na bacia, e os do sedimento, um histórico de acúmulos. Apesar do Fe e do Mn apresentarem elevada ocorrência e concentrações tanto na água quanto no sedimento, não indicam poluição por serem elementos abundantemente presentes nos solos da região. Diferentemente do $\mathrm{Pb}$ e $\mathrm{Cr}$, que ocorreram em mais de $22 \%$ das amostras de água e $65 \%$ das amostras de sedimentos, representando assim um elevado risco ambiental.

Espacialmente, os metais apresentaram baixa variabilidade nas concentrações, sem padrões lineares evidentes ao longo do gradiente longitudinal dos rios. As exceções foram o Fe e o $\mathrm{Mn}$, na parte alta do rio Vermelho, na bacia do São Lourenço, o $\mathrm{Cu}$ no ponto imediatamente a jusante da cidade de Rondonópolis e o $\mathrm{Pb}$ nas partes altas do rio Vermelho e média do rio Cuiabá, que se destacaram pelas maiores concentrações destes metais. Esses aportes estão supostamente vinculados às atividades agropecuárias e de mineração mais intensas na parte alta da bacia do São Lourenço, bem como da poluição oriunda das cidades. Temporalmente, as concentrações dos metais estiveram associadas ao regime pluviométrico da região, já que o $\mathrm{Fe}, \mathrm{Mn}, \mathrm{Zn}$ e $\mathrm{Cr}$ no sedimento, e o Fe na água, apresentaram maiores concentrações no início do período chuvoso e nos meses de maiores precipitações, respectivamente. Com isso, observa-se que o efeito da lixiviação e carreamento destes metais na bacia promovidos pela chuva, é maior que seu efeito diluidor causado pelo maior volume de água durante o período de maior precipitação.

$\mathrm{O}$ efeito indireto da chuva também pode ser observado nas correlações existentes entre o $\mathrm{Fe}, \mathrm{Mn}$ e $\mathrm{Cu}$ na água com a turbidez, indicando que o carreamento destes metais ocorre associado ao material particulado em suspensão durante o período chuvoso. Além destas, as correlações entre o $\mathrm{Fe}$ e o $\mathrm{Mn}$ com a $\mathrm{DBO}$, positivamente, e com o $\mathrm{OD}$, negativamente, indicam também que o carreamento destes elementos ocorre de forma adsorvida à matéria orgânica.

\section{IPABH}

Rev. Ambient. Água vol. 11 n. 4 Taubaté - Oct. / Dec. 2016 
Por fim, as relações observadas entre metais na mesma matriz indicam fontes semelhantes, destacando as correlações entre o $\mathrm{Cu}$ e o $\mathrm{Zn}$ tanto na água quanto no sedimento, tendo como provável origem comum a utilização de pesticidas na lavoura. Desta maneira, a ocorrência e concentração de metais na água e no sedimento dos rios Cuiabá e São Lourenço ocorrem devido à contribuição de origem natural - reflexo do tipo de solo - associada a regime pluviométrico da região, bem como à contribuição antrópica - atividades agropecuárias - e ao lançamento de efluentes não tratados nos centros urbanos. Destaca-se a necessidade de estudos mais detalhadas para a confirmação das prováveis fontes de poluição identificadas no presente trabalho, e de contínuo monitoramento de modo a subsidiar o planejamento e gestão destas importantes bacias, evitando riscos futuros principalmente para o Pantanal.

\section{AGRADECIMENTOS}

Os autores agradecem à CAPES pelo apoio com bolsa de mestrado, à FAPEMAT e ao $\mathrm{CNPq}$ pelo apoio financeiro.

\section{REFERÊNCIAS}

AHMAD, K.; AZIZULLAH, A.; SHAMA, S.; KHATTAK, M. N. K. Determination of heavy metal contents in water, sediments, and fish tissues of Shizothorax plagiostomus in river Panjkora at Lower Dir, Khyber Pakhtunkhwa, Pakistan. Environmental Monitoring and Assessment, v. 186, p. 7357-7366, 2014. http://dx.doi.org/10.1007/s10661-0143932-1

AGÊNCIA NACIONAL DE ÁGUA - ANA (Brasil) Hidroweb. Disponível em: http://www. hidroweb.ana.gov.br. Acesso em: ago. 2016

AMERICAN PUBLIC HEALTH ASSOCIATION - APHA. Part 3000, Metals. In: Standard methods for the examination of water and wastewater. $\overline{22^{\text {nd }} \mathrm{ed}}$. Washington, D.C., 2012. p. 3.1-3.106.

ARAI, T.; OHJ, M.; HIRATA, T. Trace metal deposition in teleost fish otolith as an environmental indicator. Water, Air and Soil Pollution, v. 179, p. 255-263, 2007. http://dx.doi.org/10.1007/s11270-006-9229-4

BASSO, C. J.; CERETTA, C. A.; FLORES, E. M. M.; GIROTTO, E. Teores totais de metais pesados no solo após aplicação de dejeto líquido de suínos. Ciência Rural, v.42, n.4, p.653-659, 2012.

BIAN, B.; CHENG, X.-J.; LI, L. Investigation of urban water quality using simulated rainfall in a medium size city of China. Environmental Monitoring and Assessment, v. 183, p. 217-229, 2011. http://dx.doi.org/10.1007/s10661-011-1916-y

BIZARRO, V. G.; MEURER, E. J.; TATSCH, F. R. P. Teor de cádmio em fertilizantes fosfatados comercializados no Brasil. Ciência Rural, v. 38, n. 1, p. 247-250, 2008. http://hdl.handle.net/10183/22273

BOSSO, S. T.; ENZWEILER, J. Ensaios para determinar a (bio)disponibilidade de chumbo em solos contaminados: revisão. Química Nova, v. 31, n. 2, p. 394-400, 2008. http://dx.doi.org/10.1590/S0100-40422008000200036 
BRASIL. Conselho Nacional do Meio Ambiente. Resolução CONAMA no 357/2005. Dispõe sobre a classificação dos corpos de água e diretrizes ambientais para o seu enquadramento. Diário Oficial [da] União, n. 53, 18 mar. 2005, p. 58-63. Disponível em: http://www.mma.gov.br/port/conama/res/res05/res35705.pdf. Acesso em: ago.2016.

BRASIL. Ministério do Meio Ambiente - MMA. Programa de estruturação institucional da consolidação da Política Nacional de Recursos Hídricos. BRA/OEA/01/002. Relatório Parcial - Caracterização das Unidades Naturais e Configuração Atual dos Tipos de Uso/Ocupação da Terra do Estado de Mato Grosso. Brasília, 2007. Disponível em: http://www.sema.mt.gov.br/index.php?option=com_docman\&task=cat_view\& gid $=563 \&$ Itemid=630. Acesso em: 22 nov. 2011.

CHEN, K.; JIAO, J. J.; HUANG, J.; HUANG, R. Multivariate statistical evaluation of trace elements in groundwater in a coastal area in Shenzhen, China. Environmental $\begin{array}{lllllll}\text { Pollution, } & \text { v. } & 147, \quad \text { n. } & 3, & \text { p. } & 771-780,\end{array}$ http://dx.doi.org/10.1016/j.envpol.2006.09.002

CHIARANDA, R.; COLPINI, C.; SOARES, T. S. Caracterização da Bacia Hidrográfica do Rio Cuiabá. Advances in Forestry Science, v. 3, n. 1, p. 13-20, 2016.

CORINGA, E. A. O.; COUTO, E. G.; TORRADO, P. V. Geoquímica de solos do Pantanal Norte, Mato Grosso. Revista Brasileira de Ciências do Solo, v. 38, p. 1784-1793, 2014.

COSTA, J. R. Distribuição de metais em peixes marinhos ao longo do litoral sudeste do Brasil. 2007. 43 f. Monografia (Graduação em Ciências Biológicas) - Centro de Biociências e Biotecnologia, Universidade Estadual do Norte Fluminense, Campos dos Goytacazes, 2007.

FADIGAS, F. S; AMARAL-SOBRINHO, N. M. B.; MAZUR, N.; ANJOS, L. H.; FREIXO, A. A. Concentrações naturais de metais pesados em algumas classes de solos brasileiros. Bragantia, v. 61, n. 2, 151-159, 2002.

FELIPE-SOTELO, M.; ANDRADE, J. M.; CARLOSENA, A.; TAULER, R. Temporal characterization of river waters in urban and semi-urban areas using physico-chemical parameters and chemometric methods. Analytica Chimica Acta, v. 583, p. 128-137, 2007. http://dx.doi.org/10.1016/j.aca.2006.10.011

FREITAS, E. V. S.; NASCIMENTO, C. W. A.; GOUlART, D. F.; SILVA, J. P. S. Disponibilidade de cádmio e chumbo para milho em solo adubado com fertilizantes fosfatados. Revista. Brasileira de Ciência do Solo, v. 33, p. 1899-1907, 2009

GERAldeS, M. C.; PETRONILHO, L. A.; SilVA, D. Trace elements and Pb isotope variations in galena from the Onça Gold Deposit, Mato Grosso, Brazil: fluid mixing from hydrothermal and crustal sources. Boletim IG-USP, Série Científica, v. 27, p. 8198, 1996.

GONÇALVES, H. C., MERCANTE, M. A., SANTOS, E. T. Hydrological cycle. Brazilian Journal of Biology, v. 71, n. 1, p. 241-253, 2011.

GONÇALVES, P. R. S.; OLIVEIRA, A. P.; CRUZ, I. F.; DORES, E. F. G. C. Distribuição espacial de metais potencialmente tóxicos em água superficial nas bacias dos rios Cuiabá e São Lourenço - MT. Revista Brasileira de Recursos Hídricos, v. 20, n. 1, p. 157-168, 2015. 
IKEM, A.; EGIEBOR, N. O.; NYAVOR, K. Trace elements in water, fish and sediment from Tuskegee Lake, Southeastern USA. Water, Air, and Soil Pollution, v.149, p. 51-75, 2003. http://dx.doi.org/10.1023/A:1025694315763

JUNK, W. J.; CUNHA, C. N. Pantanal: a large South American wetland at a crossroads. Ecological Engineering, v. 24, n. 4, p. 391-401, 2005. http://dx.doi.org/10.1016/j.ecoleng.2004.11.012

KER, J. C. Latossolos do brasil: uma revisão. Geonomos, v. 5, n. 1, p. 17-40, 1997. http://dx.doi.org/10.18285/geonomos.v5i1.187

KUNZ, A.; HIGARASHI, M. M.; OLIVEIRA, P. A.Tecnologias de manejo e tratamento de dejetos de suínos estudadas no Brasil. Cadernos de Ciência \& Tecnologia, v. 22, n. 3, p. 651-665, 2005.

LAABS, V.; AMELUNG, W.; PINTO, A. A.; WANTZEN, M.; SILVA, C. J.; ZECH, W. Pesticides in Surface Water, Sediment, and Rainfall of the Northeastern Pantanal Basin, $\begin{array}{llllll}\text { Brazil. Environmental Quality, v. 31, p. 1636-1648, } 2002 . & \end{array}$ http://dx.doi.org/10.2134/jeq2002.1636

LENZI, E.; ALMEIDA, V. C.; FAVERO, L. O. B.; BECKER, F. J. Detalhes da utilização do íon hidróxido, $\mathrm{HO}^{-}$, no tratamento de efluentes contaminados com metal pesado zinco. Acta Scientiarum Technology, v. 33, n. 3, p. 313-322, 2011. http://dx.doi.org/10.4025/actascitechnol.v33i3.8379

LIMA, C. R. N.; ZEILHOFER, P.; DORES, E. F. G.; FANTIN-CRUZ, I. Variabilidade espacial da qualidade de água em escala de bacias - Rio Cuiabá e São Lourenço, Mato Grosso. Revista Brasileira de Recursos Hídricos, v. 20, p. 169-178, 2015.

MACDONALD, D. D.; INGERSOLL, C. G.; BERGER, T. A. Development and Evaluation of Consensus-Based Sediment Quality Guidelines for Freshwater Ecosystems. Archives of. Environmental Contamination and Toxicology, v. 39, p. 20-31, 2000. http://dx.doi.org/10.1007/s002440010075

MATO GROSSO. Secretaria de Estado de Meio Ambiente - SEMA. Superintendência de Recursos Hídricos -SURH. Relatório de Monitoramento da Qualidade das Águas da Sub-Bacia do Rio Cuiabá - MT, 2005. Cuiabá: SEMA; SURH, 2006.

MATO GROSSO. Secretaria de Estado de Meio Ambiente - SEMA. Superintendência de Recursos Hídricos -SURH. Relatório de monitoramento da qualidade da água da sub-bacia do Rio Cuiabá 2003-2004. Cuiabá: SEMA; SURH, 2005.

MATO GROSSO. Secretaria de Estado de Meio Ambiente - SEMA. Superintendência de Monitoramento de Indicadores Ambientais. Relatório de monitoramento da qualidade da água da região hidrográfica do Paraguai - 2007 a 2009. Cuiabá: SEMA/MT; SMIA, 2010.

MATO GROSSO. Secretaria de Estado de Meio Ambiente - SEMA. Superintendência de Monitoramento de Indicadores Ambientais. relatório de monitoramento da qualidade da água da região hidrográfica do Paraguai - 2010 e 2011. Organizado por FIGUEIREDO, S. B. et al. Cuiabá: SEMA/MT; SMIA, 2014. 
MIL-HOMENS, M.: COSTA, A. M.; FONSECA, S.; TRANCOSO, M. A.; LOPES, C.; SERRANO, R.; SOUSA, R. Natural heavy metal and metalloid concentrations in sediments of the Minho River estuary (Portugal): baseline values for environmental studies. Environmental Monitoring and Assessment, v. 185, p. 5937-5950, 2013. http://dx.doi.org/10.1007/s10661-012-2996-z

MINELLA, J. P. G.; MERTEN, G. H. Aplicação das características químicas e físicas dos sedimentos na modelagem dos processos de emissão de sedimentos em bacias hidrográficas. In: MERTEN, G. H.; POLETO, C. (Orgs.). Qualidade dos Sedimentos. Porto Alegre: ABRH, 2006. p. 343-383

MORAES, D. S. L.; JORDÃO, B. Q. Degradação de recursos hídricos e seus efeitos sobre a saúde humana. Revista Saúde Pública, v. 36, n. 3, p. 370-374, 2002.

NÚNEZ, J. E. V.; AMARAL SOBRINHO, N. M. B.; PALMIERI, F.; MESQUITA, A. A. Conseqüências de diferentes sistemas de preparo do solo sobre a contaminação do solo, sedimentos e água por metais pesados. Revista Brasileira de Ciência do Solo, v. 23, p. 981-990, 1999.

PANACHUKI, E.; ALVES SOBRINHO, T.; VITORINO, A. C. T.; CARVALHO, D. F.; URCHEI, M. A. Parâmetros físicos do solo e erosão hídrica sob chuva simulada, em área de integração agricultura-pecuária. Revista Brasileira de Engenharia Agrícola e Ambiental, v.10, n.2, p.261-268, 2006.

QUEIROZ, M. T. A. Bioacumulação de metais pesados no Rio Piracicaba, Minas Gerais, aplicando a análise por ativação neutrônica instrumental. 2006. Dissertação (Mestrado em Engenharia Industrial) - Centro Universitário do Leste de Minas Gerais, Coronel Fabriciano, 2006.

RAMALHO, J. F. G. P.; AMARAL-SOBRINHO, N. M. B.; VEllosO, A. C. X. Contaminação da microbacia de Caetés por metais pesados pelo uso de agroquímicos.

Pesquisa Agropecuária Brasileira, v. 35, n.7, p. 1289-1303, 2000. http://dx.doi.org/10.1007/s11270-006-9170-6

RIETZLER, A. C.; FONSECA, A. L.; LOPES, G. P. Heavy metals in tributaries of Pampulha reservoir, Minas Gerais. Brazilian Journal of Biology, v. 61, n. 3, p. 363-370, 2001. http://dx.doi.org/10.1590/S1519-69842001000300004

RODRIGUES, M. L. K.; FORMOSO, M. L. L. Heavy metals in recent sediments and bottomfish under the influence of tanneries in south Brazil. Water, Air and Soil Pollution, v. 176, p. 307-327, 2006.

ROSA, D. B.; WESKA, R. K.; GAUTHIER, J. P.; RANTSORDAS, S.; SAMAMA, J. C. Novos dados acerca dos depósitos auríferos associados a veios de quartzo, e a degradação ambiental na porção sudoeste do município de Cuiabá - Estado de Mato Grosso, Brasil. Geoambiente on-line, n. 1, 2003. Disponível em: https://revistas.ufg.br/geoambiente/article/download/25857/14848. Acesso em: ago. 2016.

SAMPAIO, A. C. S. Metais pesados na água e sedimentos dos rios da bacia do Alto Paraguai. 2003, 76 f. Dissertação (Mestrado em Saneamento Ambiental e Recursos Hídricos) - Centro de Ciências Exatas e Tecnologia, Universidade Federal De Mato Grosso Do Sul, 2003 
SANTOS, A.; ALONSO, E.; CALlEJÓN, M.; JIMÉNEZ, J. C. Distribution of Zn, Cd, Pb and $\mathrm{Cu}$ metals in groundwater of the Guadiamar river basin. Water, Air, and Soil Pollution, v. 134, p. 275-286, 2002. http://dx.doi.org/10.1023/A:1014149107094

SANTOS, J. S.; SOUZA, F. M.; SANTOS, M. L. P. Distribuição de Zn, Pb, Ni, Cu, Mn e Fe nas frações do sedimento superficial do Rio Cachoeira na região sul da Bahia, Brasil. Química Nova, v. 36, n. 2, p. 230-236, 2013.

SHINMA, E. A. Avaliação da qualidade das águas dos rios da bacia hidrográfica do Alto Paraguai - Pantanal. 2004. 162 f. Dissertação (mestrado em Saneamento Ambiental e Recursos Hídricos) - Tecnologias Ambientais da Universidade Federal de Mato Grosso do Sul. Campo Grande, 2004.

TERRADO, M.; LAVIGNE, M.; TREMBLAY, S.; DUCHESNE, S.; VILLENEUVE, J.; ROUSSEAU, A. N. et al. Distribution and assessment of surface water contamination by application of chemometric and deterministic models. Journal of Hydrology, v. 369, p. 416-426, 2009. http://dx.doi.org/10.1016/j.jhydrol.2009.02.030

THOMÉ FILHO, J. J.; SCHISLEWSKI, G.; SHINZATO, E.; ROCHA, G. A.; DANTAS, M.; CASTRO JÚNIOR, P. R. et al. (Org.) Sistema de informação geoambiental de Cuiabá, Várzea Grande e entorno - SIG CUIABÁ. Vol. 1. Goiânia: CPRM, 2006a. 309 p.

THOMÉ FILHO, J. J.; SCHISLEWSKI, G.; SHINZATO, E.; ROCHA, G. A.; DANTAS, M.; CASTRO JÚNIOR, P. R. et al. (Org.) Sistema de informação geoambiental de Cuiabá, Várzea Grande e entorno - SIG CUIABÁ. Vol. 2. Goiânia: CPRM, 2006b. $20 \mathrm{p}$.

THOMPSON, M.; ELliSON, S. L. R.; WOOD, R. Harmonized Guidelines for Single Laboratory Validation of Methods of Analysis (IUPAC Technical Report). Pure and Applied Chemistry, v. 74, n. 5, p. 835-855, 2002.

UNITED STATES. Environmental Protection Agency - USEPA. Method 3050B Acid digestion of sediments, sludges, and soils. Disponível em: http://www.epa.gov/wastes/ hazard/testmethods/sw846/pdfs/3050b.pdf. Acesso em: maio 2011.

VIANA, A. R.; MARTA, J. M. C.; VIANA, R. R.; BATTILANI, G. A.; SALLES, T. G. Estudo de aproveitamento de rejeitos de diamante da região de Poxoréu, leste do Estado de Mato Grosso. Geociências, v. 30, n. 2, p. 161-171, 2011.

VINODHINI, R.; NARAYANAN, M. Bioaccumulation of heavy metals in organs of fresh water fish Cyprinus carpio (Common carp). International Journal of Environmental Science and Technology, v. 5, n. 2, p. 179-182, 2008.

http://dx.doi.org/10.1007/BF03326011

ZEILHOFER, P.; LIMA, E. B. N. R.; LIMA, G. A. R. Land use effects on water quality in the urban agglomeration of Cuiabá and Várzea Grande, Mato Grosso State, central Brazil. Urban Water Journal, v. 7, n. 3, p. 173-186, 2010. http://dx.doi.org/10.1080/1573062X.2010.484496

ZEILHOFER, P.; LIMA, E. B. N. R.; LIMA, G. A. R. Spatial patterns of water quality in the Cuiabá River Basin, Central Brazil. Environmental Monitoring and Assessment, v. 123, p. 41-62, 2006. http://dx.doi.org/10.1007/s10661-005-9114-4 